\title{
Penentuan Program Pengembangan IKM Dengan Pendekatan Multi Criteria Decision Making: Perspektif Faktor Internal
}

\author{
Johan K. Runtuk ${ }^{1}$ \\ 1) Industrial Engineering Department, Faculty of Engineering, President University \\ Jl. Ki Hajar Dewantara \\ Kota Jababeka,Cikarang, Bekasi - Indonesia 17550 \\ Email: johan.runtuk@president.ac.id
}

\begin{abstract}
ABSTRAK
Industri kecil menengah (IKM) merupakan unit usaha yang penting bagi perekenomian di Indonesia. Namun demikian banyak yang mengalami kesulitan untuk berkembang. Berbagai program pengembangan IKM yang diberikan, umumnya tidak terlalu memberikan dampak, tidak efektif, dan tidak berkelanjutan. Oleh karena itu, diperlukan kajian khusus untuk menentukan program pengembangan bagi IKM. Penelitian ini mengintegrasikan dua metode dalam multi criteria decision making (MCDM), yaitu metode decision-making trial and evaluation laboratory (DEMATEL) dan metode analytic network process (ANP) untuk menentukan faktor internal mana yang paling penting untuk perkembangan IKM. Berdasarkan data yang diperoleh dari para ahli dan hasil analisis, didapatkan bahwa faktor internal yang bobot terbesar bagi perkembangan IKM, secara berurutan adalah: kualitas manajerial, investasi, karakteristik pemilik usaha, dan entrepreneurial orientation. Secara lebih detail, pemahaman teknologi dan penentuan dan pencapaian target (sub faktor internal kualitas manajerial), pengembangan teknologi (sub faktor internal investasi), dan keanggotaan/keterlibatan dalam kelompok bisnis/asosiasi (sub faktor internal karakteristik pemilik usaha) merupakan hal penting bagi perkembangan IKM. Program pengembangan IKM harus fokus pada peningkatan hal-hal tersebut agar IKM di Indonesia dapat mengalami perkembangan yang berkelanjutan.
\end{abstract}

Kata kunci: program pengembangan, industri kecil menengah (IKM), decision-making trial and evaluation laboratory (DEMATEL), analytic network process (ANP), faktor internal.

\begin{abstract}
Small and medium enterprises (SMEs) play a significant role for Indonesian economy. However, many SMEs have difficulty developing its business. The various SME development programs that are provided are generally less impactful, ineffective, and unsustainable. Therefore, a special study is needed to determine the development program for SMEs. This research integrates two methods in multi criteria decision making (MCDM), i.e. decision-making method of trial and evaluation laboratory (DEMATEL) and analytic network process (ANP) method to determine which internal factors that are most important for SMEs development. Based on the data obtained from the experts and the results of the analysis, internal factor that has biggest weight for the development of SMEs are managerial quality, investment, business owner characteristics, and entrepreneurial orientation; consecutively. Moreover, technology awareness and the determination and achievement of targets (sub-factor of managerial quality), technological development (sub-factor of investment), and membership/involvement in business/association groups (sub-factor of business owner characteristics) are significant factor for SMEs development. SMEs development programs should focus on improving these factors so that Indonesian SMEs can experience sustainable growth.
\end{abstract}

Keywords: development programs, small and medium enterprises (SMEs), decision-making trial and evaluation laboratory (DEMATEL), analytic network process (ANP), internal factors.

\section{Pendahuluan}

Jumlah unit usaha di Indonesia didominasi oleh usaha mikro, kecil, dan menengah (UMKM). Sepanjang tahun 2005 - 2010 jumlah perusahaan dengan skala UMKM mencapai 99,99\% dari keseluruhan jumlah unit usaha di Indonesia dan mampu menyerap tenaga kerja rata-rata mencapai $97 \%$ dari keseluruhan tenaga kerja yang terserap di seluruh unit usaha di Indonesia. Namun demikian, tingkat persaingan yang dihadapi UMKM juga cukup kuat. Irjayanti dan Azis (2012) menyatakan bahwa UMKM di Indonesia mengalami tantangan untuk berkembang, dan bahkan beberapa ada yang tutup usaha.

UMKM memiliki peranan yang penting bagi perekonomian suatu negara. UMKM di Indonesia merupakan penopang perekonomian negara melalui penciptaan lapangan pekerjaan bagi angkatan kerja yang tidak 
terserap di usaha skala besar. Terciptanya lapangan pekerjaan ini, pada akhirnya akan mendorong berkembangnya aspek sosio-ekonomi negara, antara lain pemerataan distribusi pendapatan masyarakat dan pengembangan regional. Lebih lanjut lagi, Teruel-Carrizosa (2008) menambahkan bahwa UMKM memiliki peran strategis sebagai katalis untuk pengembangan sektor industri lokal.

Penelitian ini dilakukan pada IKM, yaitu UMKM sektor manufaktur. Acs and Audretsch (1987) menyatakan bahwa sektor manufaktur memiliki kompleksitas dalam struktur modal dan diferensiasi produk. Secara khusus, IKM di Indonesia mengalami penurunan kinerja (The World Bank, 2012). Hal ini akan berakibat buruk bagi penyerapan tenaga kerja sektor informal di Indonesia. Oleh karena itu, diperlukan suatu kajian untuk menentukan program pengembangan yang paling tepat bagi IKM di Indonesia.

Berbagai program untuk pengembangan UMKM telah banyak diberikan, baik oleh pemerintah maupun oleh akademisi. Namun demikian, dampak kebijakan-kebijakan tersebut dirasakan sangat kurang (Hoffman dkk., 1998). Sebagai contoh, Sandee dkk.(2002) melaporkan bahwa bantuan yang diberikan Pemerintah dinilai tidak efektif dan tidak berkelanjutan. Berdasarkan wawancara awal terhadap beberapa IKM, ditemukan bahwa banyak program pengembangan dan bantuan yang diberikan tidak memiliki manfaat yang berarti. Program dan bantuan tersebut cenderung fokus pada hasil jangka pendek, misalnya bantuan pemasaran dan pameran di beberapa kota atau negara.

Kajian terhadap faktor penentu keberhasilan/perkembangan IKM harus dilakukan secara sistematis. Secara khusus, penelitian ini fokus pada faktor-faktor internal IKM. Penrose (1959) menyatakan bahwa faktor internal perusahaan memegang peranan penting bagi keberhasilan usaha. Seorang manajer harus memiliki kemampuan wirausaha dan manajerial yang kuat sehingga mampu menciptakan peluang produktif. Semakin besar peluang produktif yang diciptakan, semakin besar pula peluang keberhasilan perusahaan (Lockett dkk., 2011). Faktor internal perusahaan juga penting menurut teori resource-based view (RBV). Berdasarkan teori RBV, pemanfaatan sumber daya secara tepat, melalui konfigurasi organisasi yang sesuai, akan mempengaruhi keberhasilan perusahaan (de Oliveira Wilk dan Fensterseifer, 2003).

Faktor penentu keberhasilan/perkembangan IKM ini tidak bersifat independen satu dengan lainnya, melainkan memiliki hubungan satu sama lain. Penelitian ini akan mengintegrasikan dua metode dalam multi criteria decision making (MCDM), yaitu metode decision-making trial and evaluation laboratory (DEMATEL) dan metode analytic network process (ANP). Integrasi kedua metode tersebut akan dapat menghasilkan pemahaman akan pengaruh dan dominansi dari setiap faktor terhadap berkembangnya suatu IKM, sehingga akan memudahkan bagi semua pihak dalam mengambil langkah dan kebijakan yang tepat bagi pengembangan IKM di Indonesia.

\section{Kajian Pustaka}

\subsection{Teori Pertumbuhan Usaha Menurut Penrose}

Teori pertumbuhan dari Penrose (1959) merupakan teori dasar yang banyak digunakan dalam kajian mengenai pertumbuhan usaha.Teori ini dibuat oleh Penrose setelah melakukan penelitian yang intensif pada beberapa perusahaan.Teori ini menekankan pentingnya peran manajer dalam mengeksplorasi sumber daya yang dimiliki (Lim, 2009). Suatu perusahaan, melalui peran manajernya, tidak cukup hanya mengikuti mekanisme harga saja. Sebaliknya, seorang manajer harus memiliki kemampuan wirausaha dan manajerial yang kuat sehingga mampu menciptakan peluang produktif. Pengelolaan sumber daya yang efektif akan menciptakan suatu keunikan dan keunggulan dari suatu perusahaan (Best and Humphries, 2003). Connell (2008) merangkum elemen kunci pemikiran Penrose sebagai berikut:

a. Definisi usaha sebagai kumpulan sumber daya produktif, pembagian antara kegunaan yang berbeda dan dari waktu ke waktu ditentukan oleh keputusan administratif.

b. Definisi sumber daya meliputi sumber daya fisik dan sumber daya manusia yang berisi sekumpulan layanan potensial yang dapat didefinisikan secara terpisah penggunaanya.

c. Definisi firm governance adalah kerangka administratif dimana sumber daya terikat bersama dan batasannya ditentukan oleh koordinasi administratif atau komunikasi otoritatif (meliputi kontrak, sewa, dan kesepakatan lisensi paten, yang mungkin memberikan kendali seefektif koordinasi administratif).

d. Teori proses dinamis yang dari pertumbuhan usaha yang terus berkembang namun terbatas, didasarkan pada visi/"image" wirausahawan.

e. Sebuah perspektif terhadap keterbatasan pertumbuhan usaha dan ukuran usaha.

f. Sebuah pandangan mengenai pentingnya manajer untuk menumbuhkan usaha, yaitu sebuah keuntungan/profit.

g. Sebuah pemahaman mengenai pentingnya mewarisi kemampuan manajer untuk kesuksesan ekspansi perusahaan melalui akuisisi. 
h. Sebuah pengetahuan bahwa bahkan pertumbuhan melalui akuisisi dan merger tidak luput dari batasan mengenai pentingnya menggunakan input dari sumber daya manajerial yang tersedia untuk terus menjaga koherensi organisasi.

i. Sebuah koneksi yang dibutuhkan antara pertumbuhan usaha dan peningkatan pengalaman dan pengetahuan manajemen.

j. Sebuah koneksi yang dibutuhkan antara penyelesaian pertumbuhan inkremen dan ketersediaan dari layanan manajerial yang ditujukan untuk ekspansi lebih lanjut.

k. Teori diversifikasi usaha, berdasarkan asumsi bahwa perusahaan dapat memanipulasi lingkungan agar melayani tujuan perusahaan. Penrose mengamati bahwa kumpulan peluang untuk investasi dan pertumbuhan yang ingin dicapai oleh wirausahawan dan manajer, adalah berbeda untuk setiap perusahaan dan bergantung pada kumpulan sumber daya manusia dan sumber daya lainnya.

I. Sebuah asumsi bahwa dalam teori pertumbuhan perusahaan terdapat "history matters" pertumbuhan adalah proses evolusi berdasarkan akumulasi dari pengetahuan yang dikumpulkan dalam konteks maksud/tujuan perusahaan.

Berdasarkan kajian literatur terhadap teori pertumbuhan usaha menurut Penrose, didapatkan beberapa faktor internal yang penting bagi perusahaan. Kay (2005) menekankan pentingnya investasi, baik untuk penelitian dan pengembangan maupun untuk teknologi, bagi pengembangan perusahaan. Lebih lanjut lagi, Tan dan Mahoney (2007) mengemukakan bahwa sumber daya manajerial (mis: pemahaman akan teknologi) serta intensitas dalam penelitian dan iklan mempengaruhi perkembangan perusahaan. Hal ini juga didukung oleh Clark dan Blundel (2007) yang juga menekankan pentingnya pengalaman dan pengetahuan pemilik/pengelola usaha. Hasil-hasil penelitian tersebut menunjukkan peran vital dari manajer atau pemilik usaha dalam perkembangan perusahaan.

\subsection{Teori Resources Based View (RBV)}

Resource-based view (RBV) lahir dari pemikiran Penrose (1959) dengan beberapa penyempurnaan khususnya terkait pengembangan sumber daya perusahaan untuk tetap unggul dalam kompetisi bisnis. Jacobsen (2013) menyatakan bahwa teori RBV merupakan perkembangan dari teori pertumbuhan usaha Penrose. Sumber daya dapat juga diartikan sebagai kombinasi unik dari aset dan kemampuan dalam organisasi untuk mengembangkan dan menerapkan strategi pengembangan usaha (Zubac dkk., 2010). Untuk mencapai keberhasilan, perusahaan harus terus menemukan dan meningkatkan sumber daya dan kemampuannya untuk menciptakan keunggulan bersaing dalam lingkungan bisnis yang semakin tidak menentu (Pettus, 2001).

Sumber daya dapat juga diartikan sebagai kombinasi unik dari aset dan kemampuan dalam organisasi untuk mengembangkan dan menerapkan strategi pengembangan usaha (Zubac dkk., 2010). Selain itu, perusahaan harus terus menemukan dan meningkatkan sumber daya dan kemampuannya untuk menciptakan keunggulan bersaing dalam lingkungan bisnis yang semakin tidak menentu. Kemampuan dinamis merupakan hal penting yang harus dimiliki perusahaan melalui pengelolaan sumber dayanya. Barney and Mackey (2005) mendefinisikan kemampuan dinamis sebagai kemampuan perusahaan dalam menciptakan kemampuan baru, yaitu kemampuan yang nilai potensinya dapat terealisir jika perusahaan mengimplementasikan strategi baru yang dibangun di atas kemampuan baru tersebut.

Berdasarkan kajian literatur terhadap teori RBV, didapatkan beberapa faktor internal yang penting bagi perusahaan. Westhead dkk. (2001) menyatakan bahwa karakteristik pemilik usaha merupakan faktor penting bagi kemajuan usaha. Walaupun lingkungan eksternal yang dihadapi perusahaan berubah-ubah, namun pemilik usaha yang memiliki karakteristik bisnis yang kuat, akan mampu beradaptasi dengan perubahan tersebut. Lebih lanjut lagi McKelvie dkk. (2006) menyatakan bahwa entrepreneurial orientation dari pemilik usaha memiliki peranan yang penting bagi pertumbuhan organik perusahaan. Pemilik usaha memiliki kecenderungan orientasi kewirausahaan yang berbeda-beda. Hal ini menentukan pilihan-pilihan strategi bersaing yang akan diterapkan oleh perusahaan.

\subsection{Faktor Internal Penentu Keberhasilan/Perkembangan IKM}

Berdasarkan dua teori utama yang di atas, dapat dirumuskan beberapa faktor internal yang penting bagi perkembangan Industri Kecil dan Menengah (IKM), antara lain sumber daya manajerial atau dapat disebut sebagai kemampuan manajerial, investasi yang dilakukan perusahaan, karakteristik bisnis dari pemilik usaha, dan entrepreneurial orientation. Faktor-faktor tersebut merupakan faktor internal utama yang akan menentukan berkembang atau tidaknya suatu usaha, termasuk IKM. Definisi singkat yang digunakan dalam penelitian ini untuk setiap faktor internal tersebut, termasuk penelitian-penelitian terdahulu yang mendukung faktor tersebut, dirangkum pada Tabel 1. 
Tabel 1.Rangkuman Faktor Internal

\begin{tabular}{|c|c|c|}
\hline Faktor Internal & Definisi & $\begin{array}{c}\text { Dukungan penelitian } \\
\text { terdahulu }\end{array}$ \\
\hline Kemampuan Manajerial & $\begin{array}{l}\text { Kemampuan teknis dan strategis terkait pemahaman } \\
\text { teknologi, penentuan dan pencapaian target, serta } \\
\text { pemahaman keinginan pelanggan }\end{array}$ & $\begin{array}{l}\text { Tan and Mahoney (2007), } \\
\text { Clark dan Blundel (2007), } \\
\text { Connell (2008) }\end{array}$ \\
\hline Investasi & $\begin{array}{l}\text { Komitmen perusahaan dalam pengembangan } \\
\text { teknologi, pengembangan produk, serta pemasaran }\end{array}$ & $\begin{array}{l}\text { Almus dan Nerlinger (2000), } \\
\text { Kay (2005), Calvo (2006), } \\
\text { Tan and Mahoney (2007) }\end{array}$ \\
\hline Karakteristik Pemilik Usaha & $\begin{array}{l}\text { Latar belakang pengelola usaha yang mencakup } \\
\text { pengalaman kerja, pelatihan yang diikuti, dan } \\
\text { keanggotaan/keterlibatan dalam kelompok } \\
\text { bisnis/asosiasi }\end{array}$ & $\begin{array}{l}\text { Westhead dkk. (2001), Tan } \\
\text { and Mahoney (2007) }\end{array}$ \\
\hline Entrepreneurial Orientation & $\begin{array}{l}\text { Orientasi pemilik usaha dalam mengembangkan } \\
\text { perusahaan, yang terkait dengan } \\
\text { pengembangan/inovasi, aksi proaktif, dan } \\
\text { pengambilan resiko }\end{array}$ & $\begin{array}{l}\text { McKelvie dkk. (2006), } \\
\text { Soininen dkk., 2012) }\end{array}$ \\
\hline
\end{tabular}

Berdasarkan tabel 1 dapat disimpulkan bahwa empat faktor internal utama yang menentukan berkembangnya suatu IKM. Selain itu, berdasarkan tabel di atas telah dilakukan kajian literatur dan memunculkan sub faktor internal dari setiap faktor internal yang akan diteliti. Faktor internal dan sub faktor internalnya, yang akan dianalisis dalam menentukan program pengembangan IKM, dapat dilihat pada tabel 2 .

Tabel 2.Faktor Internal dan Sub Faktor Internal

\begin{tabular}{ll}
\hline \multicolumn{1}{c}{ Faktor Internal } & \multicolumn{1}{c}{ Definisi } \\
\hline Kemampuan Manajerial & Pemahaman teknologi $\left(\mathrm{FI}_{11}\right)$ \\
$\left(\mathrm{FI}_{1}\right)$ & $\begin{array}{l}\text { Penentuan dan pencapaian target }\left(\mathrm{FI}_{12}\right) \\
\text { Pemahaman keinginan pelanggan }\left(\mathrm{FI}_{13}\right)\end{array}$ \\
& $\begin{array}{l}\text { Pengembangan teknologi }\left(\mathrm{FI}_{21}\right) \\
\text { Investasi }\left(\mathrm{FI}_{2}\right)\end{array}$ \\
& $\begin{array}{l}\text { Pengembangan produk }\left(\mathrm{FI}_{22}\right) \\
\text { Pemasaran }\left(\mathrm{FI}_{23}\right)\end{array}$ \\
Karakteristik Pemilik & Pengalaman kerja $\left(\mathrm{FI}_{31}\right)$ \\
Usaha $\left(\mathrm{FI}_{3}\right)$ & $\begin{array}{l}\text { Pelatihan yang diikuti }\left(\mathrm{FI}_{32}\right) \\
\text { Keanggotaan/keterlibatan dalam kelompok bisnis/asosiasi }\left(\mathrm{FI}_{33}\right)\end{array}$ \\
Entrepreneurial & Inovatif $\left(\mathrm{FI}_{41}\right)$ \\
Orientation $\left(\mathrm{FI}_{4}\right)$ & Proaktif $\left(\mathrm{FI}_{42}\right)$ \\
& Pengambil resiko $\left(\mathrm{FI}_{43}\right)$ \\
\hline
\end{tabular}

\subsection{Multi Criteria Decision Making (MCDM)}

\subsubsection{Metode Decision-Making Trial and Evaluation Laboratory (DEMATEL)}

Metode DEMATEL awalnya dikembangkan sekitar tahun 1972 sampai dengan 1979 oleh The Science and Human Affairs Program of the Battelle Memorial Institute of Geneva dengan tujuan untuk mempelajarai suatu permasalahan yang kompleks. Pada perkembanganya, metode DEMATEL menjadi salah satu metode terbaik yang dapat digunakan untuk menentukan hubungan cause and effect antar faktor (Tzeng dkk., 2007). Untuk menganalisis hubungan tersebut, metode DEMATEL menggunakan data yang didapatkan dari kuesioner perbandingan berpasangan pengaruh faktor.

Langkah-langkah yang dalam metode DEMATEL dijelaskan sebagai berikut (Tzeng dkk., 2007):

- Langkah 1: Dapatkan expert's opinion dan hitung rata-rata matriks Z

Pada langkah ini, akan dilibatkan grup dari $m$ expert dan $n$ faktor. Setiap expert akan diminta pendapatnya terhadap pengaruh antara dua faktor berdasarkan perbandingan berpasangan.

Derajat pengaruh faktor $i$ terhadap faktor $j$ dinotasikan sebagai $x_{i j}$. Skor berkisar antara nilai 0 (tidak ada pengaruh), 1 (pengaruh kecil), 2 (pengaruh medium), 3 (pengaruh besar), dan 4 (pengaruh sangat besar). Untuk setiap expert, sebuah matriks non-negative dibuat sebagai $X^{k}=$ $\left[X_{i j}^{k}\right]$, dimana $k$ adalah jumlah expert yang berpartisipasi dalam evaluasi faktor, dengan $1 \leq k \leq$ $m$. Jadi dengan sejumlah $m$ expert, akan dibuat matriks $X^{1}, X^{2}, X^{3}, \ldots$, dan $X^{m}$. 
Untuk mengagregasi semua penilaian dari $m$ expert, matrik rata-rata $Z=\left[Z_{i j}\right]$ dihitung dengan rumus:

$$
Z_{i j}=\frac{1}{m} \sum_{i=1}^{m} x_{i j}^{k} .
$$

- Langkah 2: Hitung the normalized initial direct-relation matriks $D$

The normalized initial direct-relation matriks $D=\left[d_{i j}\right]$, dimana nilai setiap elemen di matriks $D$ berkisar antara [0,1]. Adapun perhitungannya adalah sebagai berikut:

$$
\begin{aligned}
& D=\lambda * Z \text { atau }\left[d_{i j}\right]_{n x n}=\lambda\left[Z_{i j}\right]_{n x n}, \\
& \operatorname{dimana} \lambda=\operatorname{Min}\left[\frac{1}{\max 1 \leq i \leq n \sum_{j=1}^{n}\left|z_{i j}\right|}, \frac{1}{\max 1 \leq i \leq n \sum_{i=1}^{n}\left|Z_{i j}\right|}\right]
\end{aligned}
$$

Berdasarkan teori Markov Chain, $D^{m}$ adalah pangkat dari matriks $D$, contoh $D^{2}, D^{3}, \ldots, D^{\infty}$ yang pasti akan menghasilkan solusi konvergen pada inversi matriks, sebagai yang yang ditunjukkan pada persamaan $\lim _{m \rightarrow \infty} D^{m}=[0]_{n x n}$.

- Langkah 3: Hitung the total relation matrix T

Matriks $T$ menunjukkan total hubungan dari setiap pasangan dari faktor, yang didapatkan dari:

$$
T=\lim _{m \rightarrow \infty}\left(D+D^{2}+\cdots+D^{m}\right)=\sum_{m=1}^{\infty} D^{i},
$$

$\operatorname{dimana} \sum_{m=1}^{\infty} D^{i}=D^{1}+D^{2}+\cdots+D^{m}=D\left(\mathrm{I}+D^{1}+D^{2}+\cdots+D^{m-1}\right)=D(I-D)^{-1}$

dimana $I$ adalah suatu matriks identitas $n \times n$.

- Langkah 4: Hitung jumlah semua baris dan jumlah semua kolom matriks $T$

Pada matriks $T$, jumlah semua baris dan jumlah semua kolom, masing-masing dinyatakan dengan vektor $r$ dan vektor $c$, dimana:

$$
\begin{aligned}
& r=\left[r_{i}\right]_{n x 1}=\left(\sum_{j=1}^{n} t_{i j}\right)_{n x 1}, \\
& c=\left[c_{j}\right]^{\prime}{ }_{1 x n}=\left[\sum_{j=1}^{n} t_{i j}\right]_{1 x n}^{\prime},
\end{aligned}
$$

dimana $\left[c_{i}\right]^{\prime}$ merupakan matriks transposisi. Nilai $r_{i}$ mengindikasikan total pengaruh yang diberikan, baik langsung maupun tidak langsung, dari faktor $i$ terhadap faktor lainnya. Nilai $c_{j}$ mengindikasikan total pengaruh yang diterima, baik langsung maupun tidak langsung, yang dimiliki semua faktor lain terhadap faktor $j$. Jika $j=i$, nilai $\left(r_{i}+c_{i}\right)$ menyatakan pengaruh total, baik yang diberikan maupun yang diterima oleh faktor $i$. Sebaliknya, nilai $\left(r_{i}-c_{i}\right)$ menunjukkan kontribusi bersih dari faktor $i$ terhadap sistem. Lebih lanjut lagi, jika $\left(r_{i}-c_{i}\right)$ bernilai positif, maka faktor $i$ adalah penyebab bersih. jika $\left(r_{i}-c_{i}\right)$ bernilai negatif, maka faktor $i$ adalah penerima bersih.

- Langkah 5: Tentukan nilai threshold (a)

Pada penelitian ini, nilai threshold (a) ditentukan oleh para ahli.

- Langkah 6: Buatlah diagram cause and effect relationship

Diagram cause and effect relationship dibangun dengan memetakan semua kumpulan koordinat $\left(r_{i}+c_{i}, r_{i}-c_{i}\right)$ untuk memvisualisasikan hubungan kompleks dan menyediakan informasi untuk menentukan faktor mana yang paling penting dan bagaimana pengaruhnya ke faktor-faktor lain. Faktor dengan nilai $t_{i j}$ yang lebih besar dari $a$ adalah yang terpilih untuk ditunjukkan pada diagram cause and effect relationship.

\subsubsection{Metode Analytical Network Process (ANP)}

Metode ANP merupakan suatu perkembangan dari metode Analytical Hierarchy Process (AHP). Metode ini membantu penyelesaian masalah yang tidak pasti dan kompleks, khususnya terkait ketergantungan hubungan antar elemennya. Saaty (1999) menjelaskan bahwa metode ANP mampu mengakomodasi adanya keterkaitan antar elemen, yaitu keterkaitan di dalam satu set elemen (inner dependence) dan keterkaitan antara elemen yang berbeda (outer dependence). Adanya inner dependence dan outer dependence antar elemen pada metode ANP akan menghasilkan suatu hasil yang lebih baik, yang akan digunakan dalam pengambilan keputusan.

Langkah-langkah dalam metode ANP adalah sebagai berikut:

- Langkah 1: Buatlah suatu hirarki jaringan keputusan yang menunjukkan hubungan antar faktor keputusan.

- Langkah 2: Buatlah perbandingan berpasangan di antara faktor yang mempengaruhi keputusan.

- Langkah 3: Hitunglah relative importance weight vectors dari faktor-faktor tersebut.

- Langkah 4: Buatlah suatu supermatriks, yaitu suatu matriks yang tersusun dari relative importance weight vectors. Setelah itu, normalisasikan supermatriks tersebut sehingga angkaangka di dalam tiap-tiap kolom pada supermatriks memiliki jumlah bernilai 1 (satu). 
- Langkah 5: Hitunglah bobot akhir dengan meningkatkan supermatriks dengan $2 \mathrm{k}+1$ dimana $\mathrm{k}$ merupakan sembarang angka yang besar sampai stabilitas bobot terjadi, dimana nilai-nilai dalam supermatriks tidak berubah ketika dikalikan dengan dirinya sendiri, yang disebut sebagai konvergen.

\section{Hasil dan Pembahasan}

\subsection{Penentuan Hubungan Pengaruh Antar Faktor Internal}

Pada tahap ini akan ditentukan hubungan pengaruh antara faktor internal. Sebelum menentukan hubungan pengaruh tersebut, sebanyak 15 orang ahli dari akademisi, praktisi IKM, dan pemerintah diminta untuk menyatakan pendapatnya mengenai faktor internal dan sub faktor internal yang telah diidentifikasi dari kajian literatur dan yang digunakan dalam penelitian ini. Setiap responden menyatakan pendapat yang sama dengan hasil kajian literatur, oleh karena itu akan dilanjutkan dengan membuat hubungan pengaruh antar faktor internal.

Hubungan pengaruh ini dikembangkan melalui kuesioner yang diisi oleh responden. Responden diminta untuk memberi penilaian terhadap seluruh faktor internal, yaitu: kemampuan manajerial, investasi, karakteristik pemilik usaha, dan entrepreneurial orientation dengan skala 0 sampai 4 , yang berarti "tidak ada pengaruh (0)" sampai "sangat berpengaruh (4)". Selain itu, responden juga diminta untuk mengisi kuesioner perbandingan berpasangan berdasarkan 9 skala poin dari Saaty (1999), yang berarti "sama penting (0)" sampai "mutlak sangat penting (9)". Dari 15 responden awal, terdapat 7 responden yang melakukan pengisian kuesioner dengan benar dan lengkap. Hasil perhitungan metode DEMATEL dapat dilihat pada tabel 3 sampai dengan tabel 6 . Tabel 3 menunjukkan matrik rata-rata $Z$ yang dihitung menggunakan persamaan (1). Tabel 4 menunjukkan normalized initial direct-relation $D$ yang dihitung menggunakan persamaan (2) dan (3). Matrik total relation $T$ pada tabel 5 dihitung menggunakan persamaan (4). Total pengaruh yang diberikan dan diterima oleh faktor internal pada tabel 6, dihitung menggunakan persamaan (5) dan (6). Untuk mendapat gambar cause and effect relationship yang sesuai, nilai threshold sebesar 3,5 dipilih oleh para ahli. Gambar cause and effect relationship dari faktor internal dapat dilihat pada gambar 1 . Berdasarkan gambar 1, akan dibuat gambar 2 yaitu relasi network antar faktor internal, yang akan menjadi menjadi dasar bagi analisis dengan metode ANP selanjutnya.

Tabel 3. Matrik Rata-rata Z

\begin{tabular}{lcccc}
\hline & $\begin{array}{c}\text { Kemampuan } \\
\text { Manajerial }\end{array}$ & Investasi & $\begin{array}{c}\text { Karakteristik } \\
\text { Pemilik Usaha }\end{array}$ & $\begin{array}{c}\text { Entrepreneurial } \\
\text { Orientation }\end{array}$ \\
\hline Kemampuan Manajerial & 0,000 & 3,000 & 2,571 & 3,286 \\
Investasi & 2,000 & 0,000 & 3,286 & 3,000 \\
Karakteristik Pemilik Usaha & 3,429 & 2,571 & 0,000 & 3,143 \\
EntrepreneurialOrientation & 3,286 & 3,286 & 2,286 & 0,000 \\
\hline
\end{tabular}

Tabel 4. Matrik Normalized Initial Direct-Relation D

\begin{tabular}{lcccc}
\hline & $\begin{array}{c}\text { Kemampuan } \\
\text { Manajerial }\end{array}$ & Investasi & $\begin{array}{c}\text { Karakteristik } \\
\text { Pemilik Usaha }\end{array}$ & $\begin{array}{c}\text { Entrepreneurial } \\
\text { Orientation }\end{array}$ \\
\hline Kemampuan Manajerial & 0,000 & 0,318 & 0,273 & 0,348 \\
Investasi & 0,212 & 0,000 & 0,348 & 0,318 \\
Karakteristik Pemilik Usaha & 0,364 & 0,273 & 0,000 & 0,333 \\
EntrepreneurialOrientation & 0,348 & 0,348 & 0,242 & 0,000 \\
\hline
\end{tabular}

Tabel 5. Matrik Total Relation T

\begin{tabular}{lcccc}
\hline & $\begin{array}{c}\text { Kemampuan } \\
\text { Manajerial }\end{array}$ & Investasi & $\begin{array}{c}\text { Karakteristik } \\
\text { Pemilik Usaha }\end{array}$ & $\begin{array}{c}\text { Entrepreneurial } \\
\text { Orientation }\end{array}$ \\
\hline Kemampuan Manajerial & 3,203 & $3,501^{*}$ & 3,255 & $3,664^{*}$ \\
Investasi & 3,232 & 3,102 & 3,155 & 3,483 \\
Karakteristik Pemilik Usaha & $3,561^{*}$ & $3,563^{*}$ & 3,122 & $3,749^{*}$ \\
Entrepreneurial Orientation & 3,454 & $3,514^{*}$ & 3,233 & 3,400 \\
\hline
\end{tabular}

Tabel 6. Total Pengaruh yang Diberikan dan Diterima oleh Faktor Internal

\begin{tabular}{lcc}
\hline & $r_{i}+c_{i}$ & $r_{i}-c_{i}$ \\
\hline Kemampuan Manajerial $\left(\mathrm{FI}_{1}\right)$ & 27,073 & 0,173 \\
Investasi $\left(\mathrm{FI}_{2}\right)$ & 26,654 & $-0,708$ \\
Karakteristik Pemilik Usaha $\left(\mathrm{FI}_{3}\right)$ & 26,759 & 1,230 \\
Entrepreneurial Orientation $(\mathrm{FI} 4)$ & 27,896 & $-0,694$ \\
\hline
\end{tabular}




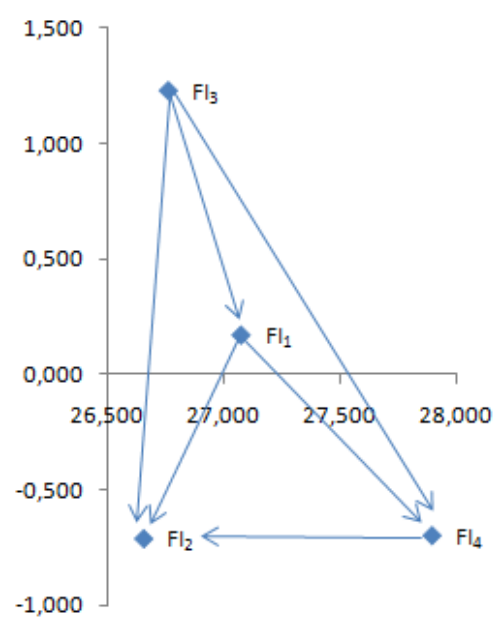

Gambar 1. Cause and effect relationship faktor internal

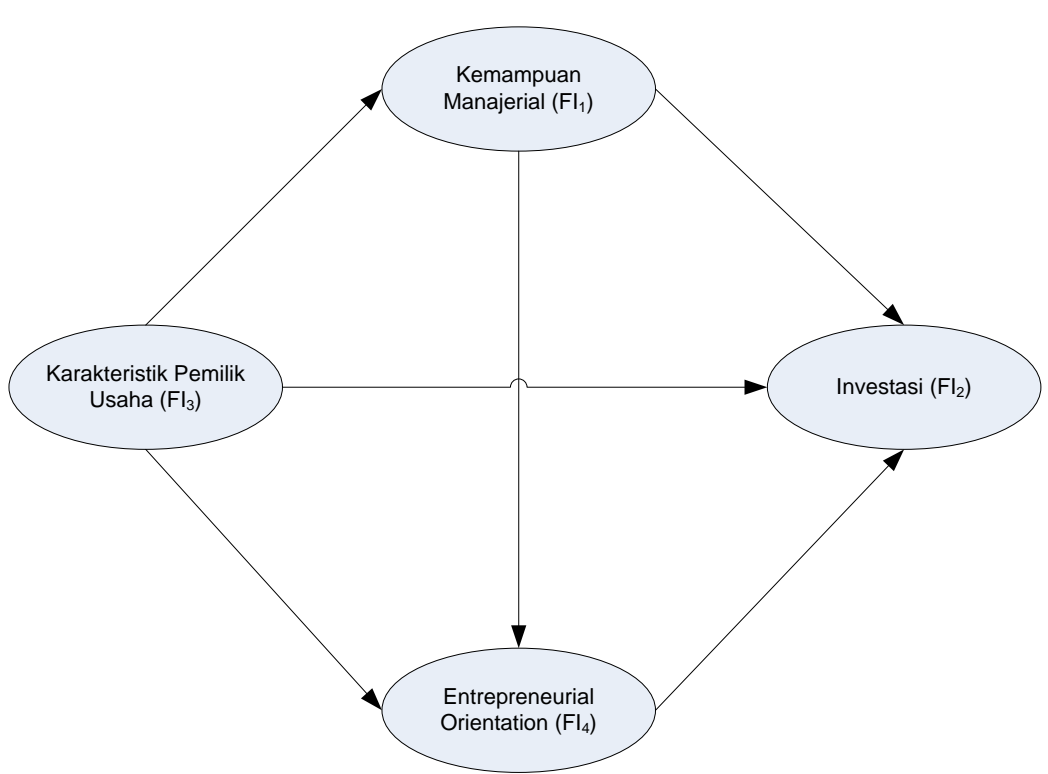

Gambar 2. Relasi network antar faktor internal

\subsection{Penentuan Bobot Tingkat Kepentingan Relatif Faktor Internal dan Sub Faktor Internal}

Bobot faktor internal dan sub faktor internal ditentukan dengan metode ANP. Pada penelitian ini, perhitungan metode ANP dikerjakan dengan menggunakan bantuan software superdecision. Tabel 7 menunjukkan bobot tingkat kepentingan dari faktor internal. Setelah itu, dilanjutkan dengan mencari bobot setiap sub faktor pada masing-masing faktor internal, yang ditunjukkan pada tabel 8 sampai dengan tabel 11 . Tabel 12 menunjukkan bobot akhir setiap sub faktor yang diperoleh dari mengalikan setiap bobot suatu sub faktor internal (pada tabel 8 sampai dengan tabel 11) dengan bobot faktor internalnya (pada tabel 7).

Tabel 7. Bobot tingkat kepentingan faktor internal

\begin{tabular}{ll}
\hline \multicolumn{1}{c}{ Faktor internal } & Bobot \\
\hline Kemampuan Manajerial $\left(\mathrm{FI}_{1}\right)$ & 0,347 \\
Investasi $\left(\mathrm{FI}_{2}\right)$ & 0,271 \\
Karakteristik Pemilik Usaha $\left(\mathrm{FI}_{3}\right)$ & 0,255 \\
Entrepreneurial Orientation $(\mathrm{FI} 4)$ & 0,127 \\
\hline
\end{tabular}

Tabel 8. Bobot tingkat kepentingan sub faktor kemampuan manajerial

\begin{tabular}{ll}
\hline \multicolumn{1}{c}{ Sub faktor internal } & Bobot \\
\hline Pemahaman teknologi $\left(\mathrm{FI}_{11}\right)$ & 0,437 \\
Penentuan dan pencapaian target $\left(\mathrm{FI}_{12}\right)$ & 0,344 \\
Pemahaman keinginan pelanggan $\left(\mathrm{FI}_{13}\right)$ & 0,219 \\
\hline
\end{tabular}


Tabel 9. Bobot tingkat kepentingan sub faktor investasi

\begin{tabular}{ll}
\hline \multicolumn{1}{c}{ Sub faktor internal } & Bobot \\
\hline Pengembangan teknologi $\left(\mathrm{FI}_{21}\right)$ & 0,385 \\
Pengembangan produk $\left(\mathrm{FI}_{22}\right)$ & 0,311 \\
Pemasaran $\left(\mathrm{FI}_{23}\right)$ & 0,304 \\
\hline
\end{tabular}

Tabel 10. Bobot tingkat kepentingan sub faktor karakteristik pemilik usaha

\begin{tabular}{ll}
\hline \multicolumn{1}{c}{ Sub faktor internal } & Bobot \\
\hline Pengalaman kerja $\left(\mathrm{FI}_{31}\right)$ & 0,343 \\
Pelatihan yang diikuti $\left(\mathrm{FI}_{32}\right)$ & 0,299 \\
Keanggotaan/keterlibatan dalam kelompok bisnis/asosiasi $\left(\mathrm{FI}_{33}\right)$ & 0,358 \\
\hline
\end{tabular}

Tabel 11. Bobot tingkat kepentingan sub faktor entrepreneurial orientation

\begin{tabular}{ll}
\multicolumn{1}{c}{ Sub faktor internal } & Bobot \\
\hline Inovatif $\left(\mathrm{FI}_{41}\right)$ & 0,317 \\
Proaktif $\left(\mathrm{FI}_{42}\right)$ & 0,299 \\
Pengambil resiko $\left(\mathrm{FI}_{43}\right)$ & 0,384 \\
\hline
\end{tabular}

Tabel 12. Bobot tingkat kepentingan gabungan

\begin{tabular}{llc}
\hline \multicolumn{1}{c}{ Faktor internal } & \multicolumn{1}{c}{ Sub faktor internal } & Bobot akhir \\
\hline Kemampuan & Pemahaman teknologi $\left(\mathrm{FI}_{11}\right)$ & 0,152 \\
Manajerial $\left(\mathrm{FI}_{1}\right)$ & Penentuan dan pencapaian target $\left(\mathrm{FI}_{12}\right)$ & 0,119 \\
& Pemahaman keinginan pelanggan $\left(\mathrm{FI}_{13}\right)$ & 0,076 \\
& & 0,104 \\
Investasi $\left(\mathrm{FI}_{2}\right)$ & Pengembangan teknologi $\left(\mathrm{FI}_{21}\right)$ & 0,084 \\
& Pengembangan produk $\left(\mathrm{FI}_{22}\right)$ & 0,082 \\
& Pemasaran $\left(\mathrm{FI}_{23}\right)$ & 0,088 \\
Karakteristik & & 0,076 \\
Pemilik Usaha $\left(\mathrm{FI}_{3}\right)$ & Pengalaman kerja $\left(\mathrm{FI}_{31}\right)$ & 0,091 \\
& Keanggotanan yang diikuti $\left(\mathrm{FI}_{32}\right)$ & 0,040 \\
Entrepreneurial & Inovatif $\left(\mathrm{FI}_{41}\right)$ & 0,038 \\
Orientation $(\mathrm{FI})$ & Proaktif $\left(\mathrm{FI}_{42}\right)$ & 0,049 \\
\hline
\end{tabular}

\subsection{Pembahasan}

Berdasarkan hasil di atas dapat dilihat adanya keterkaitan dan pengaruh di antara faktor internal penentu perkembangan IKM. Pengaruh langsung ataupun tidak langsung diketahui melalui analisis DEMATEL pada tabel 6 dan gambar 1. Tabel 6 menunjukkan bahwa faktor internal kemampuan manajerial $\left(\mathrm{Fl}_{1}\right)$ memberikan pengaruh terbesar kepada faktor internal lainnya, sekaligus juga faktor internal yang paling sedikit mendapat pengaruh dari faktor internal lain. Berdasarkan gambar 1 yang dibuat dengan nilai threshold sebesar 3,5; dapat dilihat bahwa faktor internal karakteristik pemilik usaha mempengaruhi faktor internal lain paling banyak (faktor internal kemampuan manajerial, entrepreneurial orientation, dan investasi), sedangkan faktor internal investasi tidak mempengaruhi faktor internal lain. Dengan demikian, jika ingin meningkatkan ketepatan dalam berinvestasi, maka harus memberi perhatian yang lebih terhadap peningkatan kemampuan manajerial dan karakteristik pemilik usaha, karena dua faktor ini merupakan faktor internal yang memberi pengaruh, sedangkan investasi merupakan faktor internal yang dipengaruhi.

Selain pengaruh antar faktor internal yang tidak sama, hasil penelitian ini juga menunjukkan adanya bobot tingkat kepentingan faktor internal dan juga sub faktor internal yang juga tidak sama. Dari sub bab 3.2 dapat dilihat bahwa bahwa faktor internal kemampuan manajerial merupakan faktor internal yang lebih penting bagi pengembangan IKM. Selain itu, sub faktor kemampuan manajerial, yaitu pemahaman teknologi dan penentuan dan pencapaian target memberikan bobot akhir terbesar bagi pengembangan IKM. Di sisi lain, sub faktor proaktif dan inovatif yang merupakan sub dari entrepreneurial orientation memiliki bobot akhir terkecil. Hal ini menunjukkan bahwa pengembangan entrepreneurial orientation pemilik IKM bukan merupakan program utama bagi IKM.

Dalam konteks IKM, pemilik usaha atau manajer merupakan aktor utama yang menentukan seluruh kebijakan dan strategi usaha, baik produksi, pemasaran, maupun dalam hal kerjasama. Oleh karena itu, kemampuan dan pengetahuan pemilik usaha akan sangat menentukan perkembangan dari IKM yang dikelolanya. Program pengembangan IKM terkait faktor internal harus ditentukan dengan baik sehingga diketahui program mana yang merupakan prioritas dan penting bagi perkembangan IKM. 


\section{Simpulan}

Penelitian ini menunjukkan pentingnya pendekatan metode multi criteria decision making (MCDM) untuk pengambilan suatu keputusan. Penentuan suatu keputusan atau program, khususnya bagi pengembangan IKM, harus dilakukan dengan sungguh-sungguh karena hasilnya akan berpengaruh ke satu atau lebih faktor. Sebagai contoh, hasil penelitian ini menunjukkan bahwa jika program pengembangan yang diberikan kepada IKM adalah terkait peningkatan faktor internal kemampuan manajerial dari pemilik IKM, maka hal ini berdampak juga kepada peningkatan faktor internal lain. Hal ini menunjukkan bahwa penentuan program pengembangan IKM, akan sangat menentukan efektifitas program tersebut pada perkembangan IKM.

Lebih lanjut lagi, sub-sub dari faktor internal juga berpengaruh terhadap efektifitas tercapainya suatu faktor internal. Sebagai contoh, hasil penelitian ini menunjukkan bahwa sub faktor internal pemahaman teknologi memiliki bobot terbesar dalam menentukan peningkatan kemampuan manajerial pemilik IKM. Oleh karena itu, program pelatihan yang terkait dengan pemahanan teknologi bagi IKM akan sangat berarti bagi perkembangan IKM. Demikian juga terhadap sub faktor internal yang lain, penentuan program pengembangan IKM harus dipilih menurut bobotnya. Penelitian ini memberikan pendekatan yang sistematis dalam menentukan program pengembangan IKM. Selain itu, diperlukan juga monitoring dan evaluasi terhadap setiap program yang diberikan kepada IKM, agar dapat diketahui keberhasilan setiap program terhadap perkembangan IKM.

\section{Daftar Pustaka}

1. Acs, Z.J. and Audretsch, D.B. (1987), "An empirical examination of small firm growth", Economics Letters, Vol. 25 No. 4, pp. 363-366.

2. Almus, M. and Nerlinger, E.A. (2000), “Testing 'Gibrat's Law' for Young Firms: Empirical Results for West Germany”, Small Business Economics, Vol. 15 No. 1.

3. Barney, J.B. and Mackey, T.B. (2005), "Testing resource-based theory”, Research methodology in strategy and management, Vol. 2, pp. 1-13.

4. Best, M.H. and Humphries, J. (2003), “Edith Penrose: a feminist economist?", Feminist Economics, Vol. 9 No. 1, pp. 47-73.

5. Calvo, J.L. (2006), "Testing Gibrat's Law for Small, Young and Innovating Firms", Small Business Economics, Vol. 26 No. 2, pp. 117-123.

6. Clark, P. and Blundel, R. (2007), "Penrose, critical realism and the evolution of business knowledge: A methodological reappraisal”, Management \& Organizational History, Vol. 2 No. 1, pp. 45-62.

7. Connell, C.M. (2008), "Firm and Government as Actors in Penrose's Process Theory of International Growth: Implications for the Resource-Based View and Ownership-LocationInternationalisation Paradigm", Australian Economic History Review, Vol. 48 No. 2, pp. 170194.

8. De Oliveira Wilk, E. and Fensterseifer, J.E. (2003), "Use of resource-based view in industrial cluster strategic analysis", International Journal of Operations \& Production Management, Vol. 23 No. 9, pp. 995-1009.

9. Hoffman, K., Parejo, M., Bessant, J. and Perren, L. (1998), "Small firms, R\&D, technology and innovation in the UK: a literature review", Technovation, Vol. 18 No. 1, pp. 39-55.

10. Irjayanti, M. and Azis, A.M. (2012), "Barrier Factors and Potential Solutions for Indonesian SMEs", Procedia Economics and Finance, International Conference on Small and Medium Enterprises Development, Vol. 4, pp. 3-12.

11. Jacobsen, L. (2013), "On Robinson, Penrose, and the resource-based view", The European Journal of the History of Economic Thought, Vol. 20 No. 1, pp. 125-147.

12. Kay, N.M. (2005), "Penrose and the growth of multinational firms", Managerial and Decision Economics, Vol. 26 No. 2, pp. 99-112. 
13. Lim, S.K. (2009), Dynamic resouce-based view of entrepreneurial firm growth, The University of Western Ontario, London, Ontario, Canada.

14. Lockett, A., Wiklund, J., Davidsson, P. and Girma, S. (2011), "Organic and Acquisitive Growth: Re-examining, Testing and Extending Penrose's Growth Theory", Journal of Management Studies, Vol. 48 No. 1, pp. 48-74.

15. McKelvie, A., Wiklund, J. and Davidsson, P. (2006), "A resource-based view on organic and acquired growth", Advances in Entrepreneurship, Firm Emergence and Growth, Vol. 9, pp. 175194.

16. Penrose, E. (1959), The Theory of The Growth of The Firm, OXFORD University Press.

17. Pettus, M.L. (2001), "The Resource-Based View as a Developmental Growth Pprocess: Evidence From The Deregulated Trucking Industry.", Academy of Management Journal, Vol. 44 No. 4, pp. 878-896.

18. Saaty, T.L., (1999), Decision Making for Leaders, 3rd ed., RWS Publications: Pittsburgh, PA.

19. Sandee, H., Isdijoso, B. and Sulandjari, S. (2002), SME clusters in Indonesia: An analysis of growth dynamics and employment conditions, Intl Labour Organisation.

20. Soininen, J., Martikainen, M., Puumalainen, K. and Kyläheiko, K. (2012), "Entrepreneurial orientation: Growth and profitability of Finnish small- and medium-sized enterprises", International Journal of Production Economics, Vol. 140 No. 2, pp. 614-621.

21. Tan, D. and Mahoney, J.T. (2007), "The dynamics of Japanese firm growth in US industries: The Penrose effect", Management International Review, Vol. 47 No. 2, pp. 259-279.

22. Teruel-Carrizosa, M. (2008), "Gibrat's law and the learning process", Small Business Economics, Vol. 34 No. 4, pp. 355-373.

23. The World Bank. (2012), Mempercepat Laju: Revitalisasi Pertumbuhan di Sektor Manufaktur Indonesia, World Bank.

24. Tzeng, G.H., Chiang, C.H., Li, C.W. (2007). Evaluating intertwined effects in e-learning programs: A novel hybrid MCDM model based on factor analysis and DEMATEL. Expert Systems with Applications, 32 (4), 1028-1044.

25. Westhead, P., Wright, M. and Ucbasaran, D. (2001), "The internationalization of new and small firms: A resource-based view”, Journal of business venturing, Vol. 16 No. 4, pp. 333-358.

26. Zubac, A., Hubbard, G. and Johnson, L.W. (2010), "The RBV and value creation: a managerial perspective”, European Business Review, Vol. 22 No. 5, pp. 515-538. 